\title{
Application of Public Health Risk Assessment Methodology for Typhoon Disaster in China
}

\author{
Wang Zhe ${ }^{1}$, Li Yonghong ${ }^{2}$, Zhang Bike ${ }^{1}$, Ren Jinghuan ${ }^{1}$, Jiang Fanxiao ${ }^{3, *}$ \\ ${ }^{1}$ Public Health Emergency Center, Chinese Center for Disease Control and Prevention, Beijing, China \\ ${ }^{2}$ Institute for Infectious Diseases Control, Guangxi Province Center for Disease Control and Prevention, Nanning, China \\ ${ }^{3}$ Public Health School, Tianjin Medical University, Tianjin, China
}

\section{Email address:}

wangzhe@chinacdc.cn (Wang Zhe),917738548@qq.com (Li Yonghong), zhangbk@chinacdc.cn (Zhang Bike), renjh@chinacdc.cn (Ren Jinghuan),jiangfanxiao@hotmail.com (Jiang Fanxiao)

${ }^{*}$ Corresponding author

\section{To cite this article:}

Wang Zhe, Li Yonghong, Zhang Bike, Ren Jinghuan, Jiang Fanxiao. Application of Public Health Risk Assessment Methodology for Typhoon Disaster in China. European Journal of Preventive Medicine. Vol. 7, No. 1, 2019, pp. 11-16. doi: 10.11648/j.ejpm.20190701.13

Received: December 3, 2018; Accepted: February 15, 2019; Published: March 11, 2019

\begin{abstract}
Objective We conducted a public health risk assessment program for the Guangxi Zhuang Autonomous Region for typhoon disaster, to provide scientific evidence for public health emergency response and preparedness. Methods The public health risk assessment model for natural disaster is established through literature reviews, brainstorming, Delphi's expert consultation and evaluation, based on theories of management, sociology and epidemiology. Basic data related to natural disasters and public health were extensively collected before the risk assessment. 34 public health experts from different professional fields identify the risk factors based on the basic data, conduct risk analysis according to the scoring criterion, calculate the risk values of risk factors according to the evaluation model, and then conduct the risk evaluation. Results 20 major public health risks which could seriously affect the Guangxi Zhuang Autonomous Region for typhoon disaster, were identified and assessed. The results of risk analysis showed that trauma, typhoid or paratyphoid, cholera, infectious diarrhea and hepatitis A were the top five high risk factors. Conclusion This study is the first time to apply the risk assessment theory for public health emergency preparedness before the natural disaster. Try to establish assessment index system, and then calculate risk value by semi-quantitative assessment method. This study provides a technical support for early warning surveillance and dynamic risk assessment of public health events. It will eventually improve capacity of public health emergency preparedness and response on natural disaster.
\end{abstract}

Keywords: Typhoon Disaster, Public Health, Risk Assessment

\section{Introduction}

Typhoon is one of the most common natural disasters that threaten the coastal areas of southern China. Typhoons can not only cause loss of life and property in the affected areas, but also bring a range of public health risks. It is of great practical significance to take appropriate measures to understand the public health risks caused by typhoons as early as possible and scientifically, so as to effectively prevent and respond to the public health hazards caused by typhoons. Therefore, our study takes typhoon in Guangxi Zhuang Autonomous Region as an example to explore and study the methods of typhoon public health risk assessment.

\section{Contents and Methods}

\subsection{Contents}

According to the risk assessment steps, we select the appropriate risk assessment method and assess the public health risk after typhoon in Guangxi Zhuang Autonomous Region .

\subsection{Methods}

\subsubsection{Selection of Risk Assessment Methods}

Referring to the "Risk Management Standards" formulated 
by Australia and New Zealand, the Chinese Center for Disease Control and Prevention has developed a public health risk assessment technical plan for emergencies. Based on the method of brainstorming and the Delphi, this plan includes steps such as risk identification, risk analysis, and risk assessment [1]. Delphi method uses anonymous way to consult the opinions of the members of the expert group. After several rounds of consultation, the forecast opinions of the expert group tend to be concentrated, and finally the prediction conclusion is made [2].

The assessment is divided into two rounds. The first round of assessment is to identify the risk elements of typhoon disasters. We will collect the information and send it to each expert by email. Experts will select 20 public health risk factors for typhoon disasters based on their professional background and experience in disaster relief and disease prevention.

The second round of assessment is to summarize the experts' opinions of the first round. We will send the summarized information to each expert again for analysis and judgment, for a second round of evaluation and for new opinions. We calculate the risk value through the formula: $\mathrm{R}=\mathrm{T}+\mathrm{V}-\mathrm{A}$. In this formula, "R" means the risk value, " $T$ " means the threat to risk, "V" means vulnerability, and "A" means the ability of public health resources to adapt. The threat of risk is determined by the hazard $(\mathrm{Tr})$ and probability of occurrence $(\mathrm{Tp})$, that is, $\mathrm{T}=$ $\operatorname{Tr} \times$ Tp. Vulnerability is determined by the severity of population vulnerability (Va) and the distribution of vulnerability $(\mathrm{Ve})$ that is, $\mathrm{V}=\mathrm{Va} \times \mathrm{Ve}[3]$.

\subsubsection{Implementation of Risk Assessment}

\section{i. Identify Experts}

According to the purpose of the evaluation, a total of 34 experts in the relevant public health professional fields were selected.

\section{ii. Questionnaire}

According to the purpose of the evaluation, the expert opinion consultation questionnaire is designed, including the general situation of the experts, the index of each indicator, the degree of authority of experts and so on.

\section{iii. Information Collection}

Through literature research and retrieval of Chinese disease prevention and control information system, the relevant data is collected and evaluated, which mainly includes three aspects:

(1) The data of risk factors include the number and type of public health emergencies in Guangxi in the past five years, the epidemic situation information of key infectious diseases, the characteristics of vector organisms, the distribution of toxic and hazardous chemicals, and radiation sources, etc;

(2) The population vulnerability data includes the demographic characteristics of Guangxi, focusing on the distribution characteristics of special populations such as the elderly, children, pregnant women, the immunization status of children under 12 years old, the current status of people's behavior and lifestyle, the economic level of residents and the number of floating population, etc;

(3) The adaptability data, that is, Guangxi health emergency response capability related materials, mainly including Guangxi health emergency plan system, system legal mechanism construction status, medical and health institution capacity status, emergency materials reserve status, team and equipment status, drills, and training, emergency special fund budget, etc.

\section{iv. Risk Identification}

Using the brainstorming method, the collected basic materials will be sent to the experts by e-mail. Experts are invited to list the 20 public health risks that may be faced after the typhoon disaster in Guangxi according to their professional fields and experience in disaster relief and prevention. The public health risk factors proposed by the recycling experts are sorted out and incorporate the risk factors recognized by more than two-thirds of the experts into the final risk identification form according to the principle of minority majority.

\section{v. Risk Analysis}

According to the risk factors finally determined by the risk identification form, the scientific assessment is made from the possibility, severity, population vulnerability and local adaptability of the risk, and corresponding risk disposal measures and suggestions are proposed based on the assessed risk level. The hazards of risk, the possibility of occurrence, the severity of population vulnerability, the distribution range of population vulnerability and evaluation criteria of adaptability are shown in Table 1-5. The risk value of various risks is calculated by the risk calculation formula, the ranking of each risk is listed, and the risk evaluation is performed according to the risk value level.

Table 1. Reference definition of etiology risk assignment.

\begin{tabular}{lll}
\hline Score & Comment & Definition \\
\hline 5 & $\begin{array}{l}\text { The degree of health hazard is extremely high, and the cause of this disease may cause the social impact of the event to be extremely } \\
\text { high, the public's attention is extremely high, and the government's attention is high. Such as Class A or a class of infectious disease } \\
\text { pathogens that are managed or have a high mortality rate, or highly toxic chemical materials, which are extremely harmful to nuclear and } \\
\text { radiation materials. } \\
\text { The degree of health hazard is large, and the cause of this disease may lead to the social impact of the event, the high degree of public } \\
\text { attention, and the high degree of government attention. For example, the pathogens of infectious diseases managed by Class B or Class } \\
\text { B, or the highly toxic chemical materials and nuclear and radiation materials, and the heavy nuclear and radiation materials. } \\
\text { The degree of health hazard is large, the cause of the disease may lead to a large social impact of the event, the public's attention is high, } \\
\text { and the government attaches a high degree of attention. For the most serious hazards of Class B or Class B infectious infectious agents }\end{array}$ \\
\hline high &
\end{tabular}




\begin{tabular}{|c|c|c|}
\hline Score & Comment & Definition \\
\hline & & $\begin{array}{l}\text { and severely harmful Class } \mathrm{C} \text { or Class } \mathrm{C} \text { infectious disease pathogens, or highly toxic chemicals and nuclear and radioactive materials, } \\
\text { the heavier nuclear with radiation materials. }\end{array}$ \\
\hline 2 & low & $\begin{array}{l}\text { The degree of health hazard is general, the cause of the disease may cause the social impact of the event, the public's attention is general, } \\
\text { and the government pays attention to it. For example, the pathogens of infectious diseases managed by Category } \mathrm{C} \text { or } \mathrm{C} \text {, or the toxic } \\
\text { chemicals and nuclear and radioactive materials that are more harmful, harm the general nuclear and radiation materials. }\end{array}$ \\
\hline 1 & Very low & $\begin{array}{l}\text { The degree of health hazard is small, the cause may cause the social impact of the event to be low, the public's attention is low, and the } \\
\text { government's attention is low. If the hazard is not very serious, the pathogen of infectious diseases managed by Category C or C, or the } \\
\text { less toxic chemical materials and nuclear and radioactive materials, the less harmful nuclear and radioactive materials. }\end{array}$ \\
\hline
\end{tabular}

Table 2. Evidence-based event probability assignment reference definition.

\begin{tabular}{|c|c|c|}
\hline Score & Comment & Definition \\
\hline 5 & Very high & $\begin{array}{l}\text { Almost surely cause public health events of Class I and II, such as outbreaks, epidemics, or toxic and harmful chemical pollution } \\
\text { caused by Class A or Class A, causing acute poisoning, or serious pollution of food by nuclear and radiation, The living } \\
\text { environment has caused particularly significant health impacts and presents a national trend. }\end{array}$ \\
\hline 4 & high & $\begin{array}{l}\text { It is likely to cause I, II or almost certain Class III public health emergencies, such as outbreaks, epidemics, or toxic and harmful } \\
\text { chemical pollution of Class A and B infectious diseases, which may cause acute poisoning, or nuclear and radiation food, life. } \\
\text { Environmental pollution can cause major health impact events and present trends in many cities in the province. }\end{array}$ \\
\hline 3 & Median & $\begin{array}{l}\text { May cause Class IV or high-level public health emergencies, such as local outbreaks of infectious diseases, or general poisoning } \\
\text { incidents caused by toxic and harmful chemical pollution, or general health effects caused by nuclear and radiation foods and living } \\
\text { environment pollution, and presenting the trend of many counties in the city. }\end{array}$ \\
\hline 2 & low & $\begin{array}{l}\text { It is unlikely to cause public health emergencies of Class IV and below, such as local outbreaks of infectious diseases, or general } \\
\text { poisoning incidents caused by harmful chemical pollution of the virus, or low doses of nuclear and radiation may contaminate the } \\
\text { general environment, and the events are confined to one county. }\end{array}$ \\
\hline 1 & Very low & It is highly unlikely that biological, chemical, physical and other factors generally do not cause public health emergencies. \\
\hline
\end{tabular}

Table 3. Vulnerability severity assignment reference definition.

\begin{tabular}{|c|c|c|}
\hline Score & Comment & Definition \\
\hline 5 & Very high & $\begin{array}{l}\text { The crowd includes the susceptibility, illness, disability, lethality, and mental vulnerability of the rescue team. The self-rescue and } \\
\text { mutual rescue ability is generally poor. The health resources are affected, the ability to co-ordinate health resources is poor or the degree } \\
\text { of difficulty is extremely high. Severe; or the destruction of the living environment, public health infrastructure or secondary disasters. }\end{array}$ \\
\hline 4 & high & $\begin{array}{l}\text { The crowd includes the susceptibility, illness, disability, lethality, and mental vulnerability of the rescue team. The self-rescue and } \\
\text { mutual assistance capacity is generally poor. The health resources are affected, the ability to co-ordinate health resources is poor or the } \\
\text { degree of difficulty is severe; Or the living environment, public health infrastructure damage or serious secondary disasters. }\end{array}$ \\
\hline 3 & Median & $\begin{array}{l}\text { The crowd includes the susceptibility, illness, disability, lethality, and mental vulnerability of the rescue team. The self-rescue and } \\
\text { mutual assistance capacity is generally poor. The health resources are affected, the ability to co-ordinate health resources is poor or } \\
\text { difficult. Severe; or the living environment, public health infrastructure damage or secondary disasters are more serious. }\end{array}$ \\
\hline 2 & low & $\begin{array}{l}\text { The crowd includes the susceptibility, illness, disability, lethality, and mental vulnerability of the rescue team. The self-rescue and } \\
\text { mutual rescue ability is generally poor. The health resources are affected, the ability to co-ordinate health resources is poor or the degree } \\
\text { of difficulty is not Serious; or the living environment, public health infrastructure damage or secondary disasters are not serious. }\end{array}$ \\
\hline 1 & Very low & $\begin{array}{l}\text { The population includes the susceptibility, illness, disability, lethality, and mental vulnerability of the rescue team. The status of } \\
\text { self-rescue and mutual assistance is generally negligible; or the health resources are affected, the ability to co-ordinate health resources } \\
\text { is poor or difficult. Ignore; or the living environment, public health infrastructure damage or secondary disasters can be ignored. }\end{array}$ \\
\hline
\end{tabular}

Table 4. Vulnerability attribute distribution range size assignment reference definition.

\begin{tabular}{lll}
\hline Score & Comment & Definition \\
\hline 5 & Very large & More than $80 \%$ of the population and regions last for more than one year. \\
4 & Big & More than $60 \%$ of the population and regions last for more than half a year. \\
3 & Median & More than $40 \%$ of the population and regions last for more than three months. \\
2 & small & More than $20 \%$ of the population and regions last for more than a month. \\
1 & Very small & Below $20 \%$ of the population and regions, lasting less than one month. \\
\hline
\end{tabular}

Table 5. Resource control of public health risk reviews and risk assignment reference definition.

\begin{tabular}{|c|c|c|}
\hline Risk score & Ability review & Definition \\
\hline 5 & Very high & $\begin{array}{l}\text { The plan and system are perfect, the prevention and control system is very sound, the government has strong mobilization } \\
\text { and organizational capabilities, the ability to co-ordinate health resources is extremely strong, the material reserves are } \\
\text { sufficient, or the group's emergency preventive training and drills are extremely adequate. }\end{array}$ \\
\hline 4 & high & $\begin{array}{l}\text { The plan and system are perfect, the prevention and control system is sound, the government has strong mobilization and } \\
\text { organizational capabilities, and the ability to co-ordinate health resources is strong. The material reserves are sufficient, or } \\
\text { the population's emergency preventive training and drills are sufficient. }\end{array}$ \\
\hline 3 & Median & $\begin{array}{l}\text { The plan and system are relatively complete, the prevention and control system is relatively sound, the government has strong } \\
\text { mobilization and organizational capabilities, and the ability to co-ordinate health resources is strong. The material reserves } \\
\text { are sufficient, or the population's emergency preventive training and drills are adequate. }\end{array}$ \\
\hline 2 & low & $\begin{array}{l}\text { The plan and system were initially established, and the prevention and control system was initially constructed. The } \\
\text { government's mobilization and organizational capabilities were general, and the ability to co-ordinate health resources was }\end{array}$ \\
\hline
\end{tabular}




\begin{tabular}{|c|c|c|}
\hline Risk score & Ability review & Definition \\
\hline 1 & Very low & $\begin{array}{l}\text { general. Or the population's emergency prevention training, poor practice. } \\
\text { There are no plans and systems to be established, no prevention and control system has been established, government } \\
\text { mobilization and organizational capabilities are poor, and the ability to co-ordinate health resources is very poor. Or the } \\
\text { population's emergency prevention training, drills can be ignored. }\end{array}$ \\
\hline
\end{tabular}

\subsection{Statistical Analysis}

The statistical analysis of this study was to establish a database through Excel software, and SPSS17.0 was used for statistical analysis. The reliability analysis of the consultation results mainly uses several indicators commonly used by the Delphi method, including expert positive coefficient and authority degree, etc.

\section{Outcome}

\subsection{Process of Risk Assessment}

The 34 experts are from national, provincial and municipal level three disease prevention and control institutions. They have worked in the public health field for many years, most of the experts have experience in disaster relief and disease prevention on the spot. The professional fields cover health management, information management, health emergency, infectious disease control, immunization planning, environmental health, food hygiene, radiological health, vector control, prevention and treatment of chronic diseases, etc. Among them, there are 20 senior titles, 11 deputy senior titles, 3 intermediate titles; 24 males and 10 females.

The first round of expert consultation issued 34 questionnaires, 33 were returned, and the effective response rate was $97 \%$. The degree of authority of the experts is judged according to the familiarity of the experts with the consultation indicators. The results show that the expert's familiarity with the content of the consultation is 0.71 , indicating that the consultants are authoritative and ensuring the reliability of the evaluation of each indicator.

In the evaluation, the degree of coordination of expert opinions was also evaluated. The second round of results was less than the first round of coefficient of variation. The first round of coordination coefficient was 0.35 , and the second round was 0.27 . The opinions of experts have converged and the scores tend to stabilize, indicating that the Delphi method of consultation feedback process is nearing completion.

\subsection{Conclusion of the Risk Assessment}

After two rounds of risk scoring assessment by invited experts, 20 risk factors were identified and evaluated and ranked according to their risk level, followed by trauma, typhoid or paratyphoid fever, cholera, infectious diarrhea, hepatitis A, Salmonella, Norwalk virus, influenza, bacterial dysentery, mildew food poisoning, enterohemorrhagic Escherichia coli O157:H7, leptospirosis, hand, foot and mouth disease, acute hemorrhagic conjunctivitis, heart disease, encephalitis, dengue fever, hepatitis E, medical Radiation source damage in health institutions, radiation source damage in production enterprises.

\section{Discussion}

Since the introduction of risk management and risk assessment into the public health field at the end of the 20th century, the United States has conducted risk assessment studies in the natural disaster emergency response phase [13], OSHA, FDA, WHO, UNEP, OECD, and other international organizations and organizations have formulated a series of norms and guidelines related to risk assessment based on risk assessment related research [14]. In China, risk assessment technology has been widely applied in the field of public health in recent years, playing an important role in the prevention and control of emerging infectious diseases, environmental health, food safety, mental health and other fields [15-18]. Especially in the field of natural disaster and health emergency, since the Wenchuan earthquake in 2008, the China CDC, with the support and assistance of the WHO, has carried out and completed the «Preliminary Assessment Report on the Risk of Transmission of Key Infectious Diseases in the Earthquake-Stricken Areas of Sichuan Province». Since then, in the face of major natural disasters, a series of researches and explorations on the rapid assessment of public health risks in post-disaster areas have been carried out, but it is the first time that the concept of risk assessment is introduced into the pre-disaster preparedness stage of the disaster in China.

Guangxi Zhuang Autonomous region is located in the southwest of China. Its natural geographical environment is complex, and natural disasters such as earthquakes, floods, typhoons, and other natural disasters occur frequently, especially typhoon disasters. In 2012 alone, it was hit by four typhoons, causing rainstorm, floods, and mudslides, a total of more than 3.3 million people has been affected by such disasters. This study is the first attempt to assess the public health risks that may be caused by the typhoon in the Guangxi Zhuang Autonomous Region before the occurrence of natural disasters and provides some scientific basis for the region to strengthen its awareness of the public health risk of typhoon natural disasters and make targeted preparations. At the same time, this study applies the brainstorming method and the Delphi method, which are more common in the field of risk assessment, to be applied to the typhoon disaster public health risk assessment field. It is a useful attempt and provides a reference for the risk assessment of natural disasters in the future. In particular, the evaluation index system established during the assessment process also provides a reference for the dynamic assessment of the risk of natural disaster public health events and the establishment of early warning index system.

In addition, through the public health risk assessment before the typhoon disaster, selected focus on public health 
risks, which is conducive to the local medical and health institutions to develop and revise various typhoon disaster health emergency work plans, in order to respond to typhoon disasters. The preparations provide the basis for decision-making and greatly reduce the hazards, economic losses and social impacts of various risks in the face of typhoon disasters. At the same time, due to the formulation of sound and scientific emergency plans and guarantees its implementation, it needs to consume a lot of resources, such as human, material and financial resources. Knowing the possible public health risks in advance can ensure that the prevention and control of the key risk factors with higher risks can be given priority in practical work, so as to realize the optimal allocation of public health resources and to maximize the protection of the health of the population [12].

In this study, the 20 most likely public health risks after the typhoon disaster occurred in Guangxi Zhuang Autonomous Region were selected, and the risk degree was evaluated and ranked. The top five are trauma, typhoid or paratyphoid, cholera infectious diarrhea, and hepatitis a, which is consistent with the results of studies at home and abroad that the most likely public health risks caused by typhoon disasters are trauma, gastrointestinal diseases, skin diseases and insect-borne infectious diseases [4-8]. However, the United States conducted field epidemiological studies after the hurricane in 2004 and found that psychological damage after the typhoon crisis should not be ignored. However, psychological diseases did not appear as the main public health risk after the typhoon disaster occurred in the results of this study, which may be related to the small number of experts engaged in the field of mental health and mental health [9-10]. This also reflects that the choice of experts will affect the results of using the Delphi method to assess public health risks [11].

The risk value calculation method used in this study is based on the functional relationship of each evaluation index in the risk assessment comprehensive index model and is easily deviated from the result of the expert consultation. Moreover, the method also has certain subjectivity when assigning values. The assignment of the same risk factors by different experts will be different due to different fields of expertise, work experience and field experience, which will lead to certain deviations in the final results. It is expected that when relevant research is carried out in the future, the corresponding coefficients can be standardized on each evaluation index based on previous experience, and at the same time, the functional relationship in this study can be adjusted to weaken similar deviations, further optimize the evaluation process and reduce subjective Value, increase objectivity, form a more scientific assessment summary [19].

\section{Conclusion}

The frequency and intensity of natural disaster events increase gradually, how to minimize the negative effects of natural disasters for health will be an important topic in the public health field. With the continuous improvement of the post-disaster emergency response, the future work of public health will focus on the pre-disaster phases, especially develop the public health risk assessment before natural disaster. Identify the public health risks in disaster-prone areas. And timely formulate the appropriate adaptive policies to improve the local population's health and the ability to adapt for natural disasters.

\section{Acknowledgements}

We highly appreciate the help from the GuangXi Province Center for Disease Control and Prevention in field public health risk assessment in typhoon disaster. We also indebted to the experts from provincial $\mathrm{CDC}$ in natural disaster emergency management and public health risk assessment for their participation and cooperation.

\section{Project Fund}

Operation of Public Health Emergency Response Mechanism, Chinese Center for Disease Control and Prevention (131031001000015001).

\section{References}

[1] HUANG Zhuhang, ZHANG Lizhen, ZHAO Xinhua. Application of Delphi method in epidemiological research [J]. Chinese Journal of Public Health Management, 2011, 5 (27):459-461.

[2] WANG Ruiping, GUO Xiaoqin, BI Anhua. Communicable Disease Risk Evaluation during 2010 Shanghai Expo in Songiiang district in Shanghai [J]. Disease Surveillance, 2011, 4 (26): 305-309.

[3] HONG Rongtao, ZHANG Bike, YAN Yansheng. A preliminary study on public health risk assessment methods for natural disasters [J]. Chinese Journal of Public Health Management, 2013 (2):154-158.

[4] Malilay J. Tropical cyclones. In: Noji EK, ed. The public health consequences of disasters. New York, NY: Oxford University Press, 1997.207-227.

[5] GONG Zhenyu, CHAI Chengliang, Tu Chunyu etc. A field epidemiological study on the risk factors of injury caused by typhoon $[\mathrm{J}]$. Chinese Journal of Epidemiology, 2006, 27 (9):773-776.

[6] Na W, Lee KE, Myung HN, et al. Incidences of Waterborne and Foodborne Diseases After Meteorologic Disasters in South Korea, Ann Glob Health 2016; 82:848-57.

[7] Zheng J, Han W, Jiang B, et al. Infectious Diseases and Tropical Cyclones in Southeast China, Int J Environ Res Public Health 2017; 14:10.3390/ijerph14050494.

[8] Ahmed QA, Memish ZA. The public health planners' perfect storm: Hurricane Matthew and Zika virus, Travel Med Infect Dis 2017; 15:63-6.

[9] Amber M. Henslee Scott F. Coffey Julie A, et al. Religious Coping and Psychological and Behavioral Adjustment After Hurricane Katrina, The Journal of Psychology.2015, 149 (6):630-642. 
[10] Woodruff LA Hoffpauir SA. Effective mental health response to catastrophic events: lessons learned from Hurricane Katrina. Family \& community health. 2018, 31 (1):17-22.

[11] JIANG Bo, GAO Yuxia, XING Shenyang. Application of Delphi method in the nursing study of community health service [J]. MODERN NURSING, 2007, 13 (28):2691-2693.

[12] PANG Xinghuo, LIU Xiuying, GAO Ting etc. Methodology of risk assessment for major public health events during Beijing 2008 Olympic Games [J]. CAPITAL JOURNAL OF PUBLIC HEALTH, 2009, 3 (2):52-58.

[13] Rodriguez. SR, Tocco. JS, Mallonee. S, Smithee. L, Cathey. T, Bradley. K. Rapid needs assessment of Hurricane Katrina evacuees-Oklahoma, September 2005. Prehospital and disaster medicine, 2006, 21 (6):390-5.

[14] WANG Jing. The past, present and future of risk assessment and risk management. JOURNAL OF HEALTH TOXICOLOGY, 1999, 13 (1):64-65.

[15] Li Weixiao, Chen Peirui, Shao Jindong, et al. Quantitative analysis and health risk assessment of polycyclic aromatic hydrocarbons in edible vegetable oils marketed in Shandong of China. Food and Chemical Toxicology, 2015, 83:61-67.

[16] Yi, Yujun Tang, Caihong Yi, Tieci Yang, Zhifeng Zhang, Shanghong. Health risk assessment of heavy metals in fish and accumulation patterns in food web in the upper Yangtze River, China. Ecotoxicology and Environmental Safety, 2017, 145 (Nov.):295-302.

[17] Teng, Yue Bi, Dehua Xie, Guigang Jin, et al. Model-informed risk assessment for Zika virus outbreaks in the Asia-Pacific regions. Journal of Infection, 2017, 74 (5):484-491.

[18] ZHANG Ruimei. pplication of risk management in psychiatric nursing management. JOURNAL OF NURSING ADMINISTRATION, 2006, 22 (9):70-71.

[19] ZHOU Xiaotao, XING Sizhong, ZHU Zhiliang etc. Application of risk matrix model in risk assessment of public health system in baoan district, shenzhen city. For All Health, 2013, 7 (4):68-71. 